
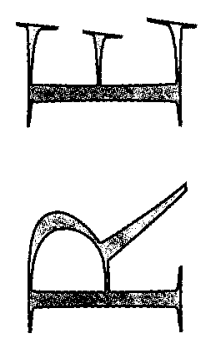

\title{
Pharmaceutical Benefits Attract New and Current Health Care Purchasers
}

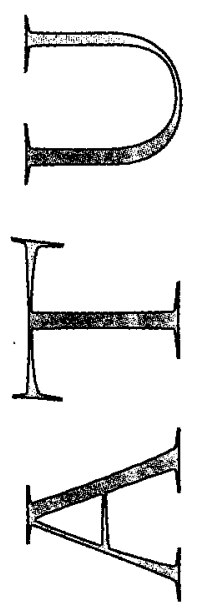

Managed care pharmacists are communicating with three key groups in an effort to enhance market share: employers, senior citizens, and potential customers wanting information-intensive pharmaceutical services. Here's how.
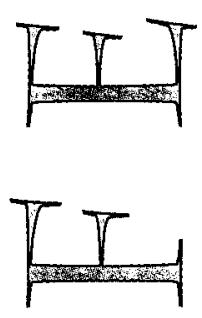

\section{E L A I N E Z A B L O C K I}

ELAINE ZABLOCKJ is a freelance medical writer in Arlington, Virginia. She is a contributing editor of The Quality Letter for Healthcare Leaders and writes regularly for many health care publications.

Copyright (C) 1996 Academy of Managed Care Pharmacy, Inc. All rights reserved. $\pi$ s competition heats up in manA aged care markets, pharmacists and marketing personnel are teaming up in an effort to publicize the many benefits of programs providing progressive pharmaceutical care. In both pharmacy benefits management companies (PBMs) and managed care organizations (MCOs), astute managers are expanding educational efforts explaining the benefits of managed pharmaceutical care.

New and current purchasers of health care services are targeted by PBMs and MCOs to alter the perception that pharmacy is an optional benefit. As the Medicare risk market grows, many MCOs are publicizing pharmaceutical benefits as a way to attract senior citizens. Third, potential customers who require information-intensive, valueadded pharmaceutical care are contacted by PBMs and MCOs able to provide this level of service. 


\section{EMPLOYERS SEEK VALUE-ADDED SERVICES: BENEFITS MANAGERS SPEAK TO PHARMACISTS}

Employers are becoming more sophisticated and precise in their negotiation for managed pharmaceutical benefits "In the past, employee benefits managers often spent their time primarily dealing with health plans, and pharmacen

care just sort of tagged along, "recalls Fred Hamacher, vice president for compensation and benefits at Dayton Hudson in Minneapolis. "We were not knowledgeable about pharmacy benefits, and we didn't focus on those issues Now employers are starting to concentrate nore on the pharmaceuti cal aspects of health care. What do employers look for? First, says Hamacher, they need more background information on how pharmacy programs work wharmacy benefits managers need to explain their role, what they do, how they add value. I'm always looking for added value. In the past, employers did not real ize the cost mplications of pharmaceutical care, especially fo retiree populations. Pharmaceutical managers today need to Weducate employers about the benefits as well as the costs of pharmaceutical care

In addition, health plans should enphasize the ways In addition health plans should emphasize the ways
they use accumulated data to improve providers'-practice pa terns, particularly in prescribing cost-effective medication; Hamacher suggests. Another aspect of value-added care is more sophisticated management of specific diseases "Data Fare just data, he says. "Unless you use the data, they are worthless. Organizations can really add yalue by taking data and puting them into useful forms, and by disseminating in formation to the provider conmunity about which medicaHons really work. These are the kinds of programs that cut ting-edge employers are looking for:"

In fact the Midwest Business Group on Health (MBGH) an Illinois-based coalition of majoremployers recently selected a pharmacy benefits manager to serve the needs of coalition members lt chose ValueRx, basedin Bloomington, Michigan.

We have a diverse group of member companies, and we needed a flexible program. explains MBGH vice president Lany Boress. "It had to meet the requirements of companies with varying cultures, politics, and personalities Some companies have a strong interest in generic drugs, while for others that's not a najor concern. Some companies believe the employee should bear a percentage of the cost while others only want a minimal copayment; he said MBGH looked for a program that would offer a retail network, a mail-service option, and a combined program, depending on each compa ny's preference Another priority: competitive rates that would decrease as the number of participants increased.

Boress agrees with Hamacher that employers today seek a sophisticated use of data, as well as lower costs. "Just offering discount drugs would not be sufficient for our members, he says "Employers seekvalue-added services. They want in formation on how their population is using pharmaceutical benefits, disease management programs for high-risk conditions, programs that help people self manage their medica tions, and programs that enhance communication between the pharmacist and prescribing physicians so there is less potential for error?

The coalition began offering Valuekx to its members in January, 1996 , since many members have existing multiyear contracts, they may not have the option of participating in the pew program until 1997 or 1998 o w
In this article, I discuss the marketing now underway to these "external" customers. In the second feature in this issue of JMCP, similar efforts directed toward internal decision-makers are detailed.

\section{ADDITIONAL EDUCATION NEEDED FOR LARGE PAYERS}

"First, we face an educational problem with large employers," says Judie Vermilyea, a consultant at Scott-Levin, in Newtown, Pennsylvania. "Too often they think of pharmacy as the extra benefit you can throw in if you want to. I work with pharmacy directors around the country, and one of the most common complaints I hear is that employers think of pharmacy as a separate item, and focus only on cutting the number of prescriptions per member per month. We need to educate corporate benefit managers so they understand that pharmaceutical care is an integral part of health care. Through appropriate use of pharmaceuticals, you can lower your hospitalization rateand overall costs can be lowered."

Some employers already understand the advantages of managed pharmaceutical care and are actively seeking sophisticated, fully integrated services (see above sidebar). But employers vary widely in their level of understanding. Kim Babbin, Pharm.D., a consultant and national practice leader for Towers Perrin, says about one half of U.S. em ployers, which cover $70 \%$ of employees, already have extensive experience with managed pharmaceutical care and today are interested in more information-intensive programs (see later discussion about such services).

These employers typically already have a community pharmacy network integrated with a mail-service option. They probably rely on a traditional use-review program, and they may have a voluntary formulary. "These employers are looking for additional levels of managementand additional cost savings," Babbin says. "They are seeking a higher level of service, in improved customer service and account management, as well as more sophisticated clinical pharmacy programs, disease state management, outcomes management, and programs that look at

Continued on page 471 
the effects of various drug therapies on employee work attendance."

The other $50 \%$ of U.S. employers generally use a traditional indemnity program, perhaps with a mail-service option. Or they may use a health-management organization (HMO) without really focusing on the level of pharmaceutical services provided. These employers are not receiving the maximum benefit possible from fully integrated pharmaceutical services, and they are a potential target for increased educational efforts.

\section{INTEGRATED SERVICES AS SELLING POINT TO LARGE PAYERS}

Fully integrated MCOs use their extensive patient database to appeal to new purchasers, says Patricia Wilson, of Associates and Wilson in Rosemont, Pennsylvania. "One of the advantages of the HMO is that they have so much information about the patient. They have medical data, laboratory test data, and the pharmaceutical record. If HMOs wish to be effective, that complex body of data could be at the core of a very appealing message."

However, while most managed care organizations do have this mass of data available from a wide variety of sources, it is often not in usable form. The laboratory, pharmacy, and physician's office each may have separate computer systems that are not able to share information.

"If an HMO wishes to market these services successfully, it must be able to integrate data efficiently," Wilson says. "It has to be able to take the information, put it into usable form as an integrated electronic record, and then use it to not only manage the quality of care, but also to manage costs. It should be able to capture and use data in spotting potential problems early and targeting interventions. The HMO must develop and use advanced technology - at present, this is where many HMOs fall flat on their faces."

Many large integrated MCOs are currently working to upgrade their data-processing systems. Within the next five years, many more health plans will use this sort of integrated patient record in marketing themselves to new customers and to compete more strongly with PBMs.

\section{PHARMACY A KEY BENEFIT FOR THE ELDERLY}

In addition to employers, who make health care purchasing decisions on behalf of large groups, Americans eligible for Medicare represent another potential target for increased education about managed pharmaceutical benefits. Elderly Medicare beneficiaries make their own individual health care purchasing decisions and have the freedom to change plans at will.

"Almost all HMOs now are attempting to market to seniors," Wilson says. "One of the selling points they use is that they offer benefits not covered by Medicare. Saying 'we're going to offer you these pharmaceutical services' is marketing in and of itself. Keep in mind that HMOs have many obstacles to overcome in dealing with the senior population. For one thing, seniors tend to have very strong allegiance to the physicians with whom they have dealt for extended periods of time. You have to do something compelling to persuade seniors to change physicians."

Pharmaceutical benefits are a major marketing tool that can strongly influence seniors' health care decisions. For example, CareData Reports of New York surveyed more than 2,500 members of Medicare HMOs in California. The 1995 analysis reflected that prescription drug coverage was a reason for selecting a particular plan for $70 \%$ of beneficiaries. Prescription drug coverage was the most frequently selected item on the list of 15 different items that might affect consumer choices.

Many MCOs have developed services designed to appeal specifically to the rapidly growing Medicare risk market. Barbara Wipf, a consultant in the Atlanta office of Towers Perrin, says, "Some of these programs actually price pharmacy almost at a loss. They make their pharmaceutical program so entic- ing or affordable that retirees or people who need a good deal of medication will select a plan based on just that information. Medicare HMOs publicize their benefit package, lower copayments, or faster mail service-pharmaceutical care is a very visible benefit."

Health plans are using a wide variety of advertising methods to inform seniors about their pharmaceutical programs, including aggressive local campaigns using radio, billboards, and print ads posted on public transportation.

SecureHorizons, a division of California-based PacifiCare, serves more than 330,000 Medicare members on the West Coast. It makes special presentations on its program to groups of senior citizens, emphasizing benefits that reach beyond standard Medicare coverage, including prescription drugs. The senior citizen market, very responsive to pharmaceutical benefits, is equally sensitive to comparisons among different benefit packages, says Valerie Consolo, market director, SecureHorizons, Sales, Southern California. "We're seeing a benefit war right now, not a price war, since almost all HMOs in California have no additional charge for Medicare recipients. We find that someone may enroll in SecureHorizons, where they get a $\$ 2,500$ annual pharmacy benefit; if they learn two weeks later that another HMO offers unlimited prescription benefits, we may lose that

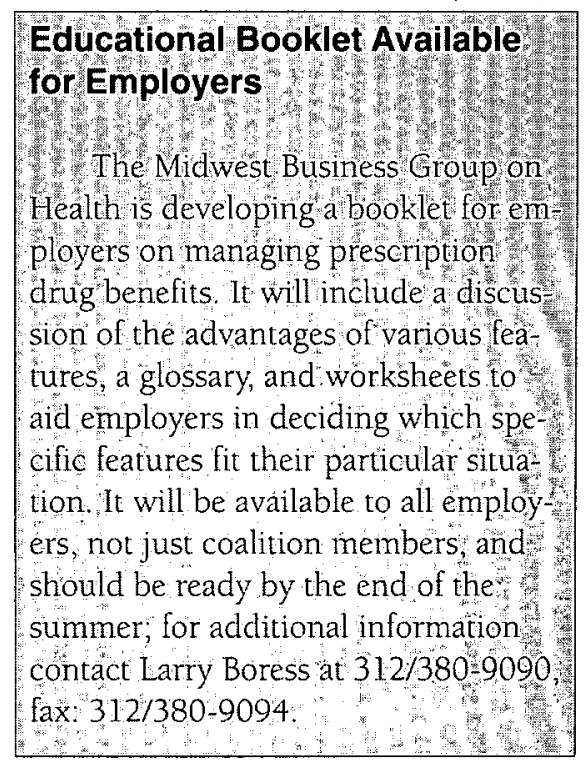


person to the competition. Even if they do not currently use pharmacy benefits, they still shop very carefully."

\section{VALUE-ADDED SERVICES OFFER ADVANTAGE FOR PBMS}

According to Blair Jackson, vice president for public relations for PCS Health Systems, Phoenix, Arizona, many potential customers are very interested in new, information-intensive, value-added pharmaceutical services.

PCS recently began Performance Rx, a preferred drug program implemented at the community pharmacy level. In certain drug classes, two or three medications are selected as the most cost-effective. When a member comes into the pharmacy with a drug not on the "preferred" list, the pharmacist obtains permission from the patient to contact the physician about a change to the preferred drug.

In late June, PCS launched disease-management programs for asthma, diabetes mellitus, ulcers, upper respiratory infections, depression, and elevated cholesterol levels. These programs use educational and behavior-modification interventions to help patients better manage their diseases.

According to Jackson, interest is high in these information-added pharmaceutical services. "We serve four types of organizations: self-insured employers, insurance companies, Blue Cross/Blue Shield, and MCOs. Across the board, we find a high degree of interest in these services. All our proposals address our ability to provide this sort of program."

The Performance Rx program, instituted last January, now has grown quickly to include 5 million members. Comparable data are not yet available for the disease-state management program, but Jackson reports, "All of our customers are asking about it. I think there is a growing realization that if you can manage pharmaceutical prescription therapy and improve compliance, you save a lot of money down the road in medical costs such as surgeries, hospitalizations, and emergency room use."

\section{DRIVING CHANGES IN BENEFIT DESIGN}

Pharmacists should spearhead efforts by managed care plans to ensure that beneficiaries receive the pharmaceutical care they need. Only by adding medications to the benefits plan can this be a certainty. Through proper marketing, pharmacists can spread the message of the advantages of medications over most other modalities of care.
This program will provide an overview of HIV/AIDS and the societal impact of the diseases from medical, economic, and patient perspectives. The management of HIV/AIDS and the clinical and economic implications of different treatment strategies on healthcare outcomes will be discussed.

\section{TARGET AU DIENCE}

Managed care pharmacy clinicians and managers who are interested in learning more about approaches to pharmaceutical care of patients with HIV and AIDS and the impact of these conditions on patients and the healthcare of system.

\section{LEARNING OBJECTIVES}

After attending this program, the participant should be able to:

1. Describe the epidemiology of HIV/AIDS.

2. Give examples of the psychologic consequences and quality-of-life issues associated with HIV/AIDS.

3. Summarize the various treatment options available for the management of HIV/AIDS.

4. List and describe newer pharmacotherapeutic agents available for HIV/AIDS.

5. Explain the impact of disease management programs on healthcare outcomes and costs of HIV/NDS.

\section{PROGRAM AGENDA}

Thursday, October 31, 1996

\section{2:00 PM Registration/Lunch \\ 12:45 PM Program Overvicw \\ 12:50 PM Epidemiology of HIV and AIDS Faculty to be announced}

1:25 PM Quality of Life Perspectives of the Patient with HIV/AIDS

MARK S. SENAK, JD

Director, Policy and Planning AIDS Project LA Los Angeles. $C A$

2:00 PM Break

2:10 PM Evaluating Treatment Options and Developing a Treatment Care Plan for Your Patient. R. Scott HitT. MD, Chairman President Clinton's Advisory Council on HIV/AIDS , Los Angeles, $C A$

3:25 PM Question \& Answer Session

4:15 PM Program Conclusion

CONTINUING EDUCATION CREDIT

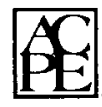
The Academy of Managed Care Pharmacy (ANCP) and Nedicall Education Systems. Inc. (NES) are

approved by the American Council on Pharmaceutical Education as providers of continuing pharmaceutical education ANCP and WES have assigned 0.35 Clits or 3.5 contact hours of continuing pharmaceutical eflucation credit. ACPE provider number $233-777-96-(149-1,02$. This program is acceptable for continuing pharmaceulical education credit, which will be awarded lree of charge via mail wilhin 4 weeks of the program to participants who atlend the program for its duration and turn in a completed cvalualion form at its conclusion. REGISTRATION INFORMATION

Contact Shelley Schoenfeld or Lorraine Hoilien at Medical Education Systems, Inc.

BY PHONE: (215) 665-1060

BY FAX: (215) 665-1210

BY MAlL: 1800 John F. Kennedy Boulevard, Suite 800 . Philadelphia. PA 19103-7415

Supported by an unrestricted educational grant from Merck US Human Health Division 